\title{
Legitimidad, poder y saber en Hesíodo. Conflictividad social y constitución ética
}

Recibido: 21/06/2018. Aceptado: 30/05/2019

\begin{abstract}
Resumen
El objetivo de este trabajo es analizar la figura del rey justo, presente en Teogonía y territorializarlo en el linaje diurno que es una de las tantas formas que encarna la dicotomía de lo Mismo en su contraposición con lo Otro. En esa territorialización el rey cumple la función de sostenedor de un orden que emana de los dioses y cuyas características se encuentran en los adjetivos asociados a su figura.
\end{abstract}

PALABRAS CLAVE: Rey; justicia; orden; conflicto; linaje

Legitimacy, power, and knowledge in the Hesiod's work. Social conflict and ethical constitution

\begin{abstract}
The objective of this paper is to analyze the figure of the king of justice, present in Theogony and territorialize him in the luminous lineage that is one of the many forms that embodies the dichotomy of the Same in its contrast with the Other. In this territorialization the king fulfills the function of sustaining an order that emanates from the gods and whose characteristics are found in the adjectives associated with his figure.
\end{abstract}

KEYWORDS: King; justice; order; conflict; linage 


\section{Introducción: La lógica del linaje}

El propósito del presente trabajo es relevar la figura del rey justo en Teogonía, proponiendo una lectura tendiente a rastrear el linaje positivo en el que se inscribe; esto implica situarse en la lógica del linaje que definiremos. Por ende comenzaremos poniendo de relieve el registro privilegiado del elemento luminoso, tanto en las divinidades como en los hombres, luminosidad esta que, propia de un linaje diurno, representa una pieza clave en su configuración identitaria.

A partir de la inscripción del rey en un plano luminoso nos proponemos pensar la problemática del poder, asociada a la legitimidad de su conducta y del modelo de vida que sostiene, en franca solidaridad con la idea de Justicia. Es necesario pues, abordar el dispositivo del linaje presente en el pensador de Ascra. El lenguaje propio de Hesíodo se inscribe en la lógica del linaje como operador discursivo, herramienta que el poeta utiliza para la institución de un cierto sentido, a partir de la consideración del mito como un lógos explicativo.

Los linajes se instituyen, ordenan la realidad, la clasifican, distribuyen los valores, definen estructuras mentales de juicio, de conocimiento, de acción (Colombani, 2016:17-37). Estos linajes redefinen el valor que tienen las divinidades y, a diferencia del estructuralismo, los campos o espacios simbólicos no son solo expresiones de una mente universal invariante, sino, más bien, expresiones de un nuevo eîdos (Foucault, 1964) que se está instituyendo; expresiones de una nueva herramienta, têukhos, un instrumento creado desde las propias condiciones de posibilidad de lo histórico-social, para comprender lo real y así ver el orden de lo visible y de lo decible, en términos foucaultianos; en última instancia para nombrar la nueva trabazón entre las palabras y las cosas (Foucault, 1964).

El discurso hesiódico abre el campo de emergencia de una determinada forma de ver y de nombrar la realidad. El discurso otorga las reglas de formación (Foucault, 1983) y en esas reglas la lógica del linaje es precisamente la herramienta que permite la tarea interpretativa. No solo define qué se ve y qué se dice, sino que, además, define cómo el discurso se articula con las prácticas sociales. Se trata, en definitiva, de ver cómo el discurso hesiódico representa un modo posible de ver y de nombrar el mundo. Las regiones de lo visible y de lo decible son esas estructuras discursivas que parecen atravesar el texto como coordenadas de problematización (lo humano y lo natural, lo humano y lo divino, etc.). Estas estructuras definen en parte las propias prácticas sociales, es decir, cómo los hombres se relacionan con los dioses, con otros hombres, con la naturaleza.

Podemos pensar el complejo universo de los linajes y las tensiones que están presentes en el interior de su lógica: Mismidad-Otredad, CosmicidadA-cosmicidad, Sophrosýne-Hýbris, Luminosidad-Oscuridad, PositividadNegatividad, Legalidad-Ilegalidad, Límite-Kháos. Si pensamos, por ejemplo, en la tensión Mismidad-Otredad (Garreta y Belleli, 1999), díada transversal del corpus hesiódico, la podemos relevar como categoría tanto divina como antropológica. En esta línea podemos pensar a la otredad que refleja el plano divino en las figuras negativizadas y animalizadas, como contribuyentes de una diversidad política encarnada en la figura de dorophágoi.

Consideramos que al quedar definida la otredad entre las potencias y los dioses, Hesíodo también está definiendo las otredades entre los hombres, tanto 
ética como políticamente hablando. El hombre que no trabaja está, según esta lógica, emparentado con el rey devorador de regalos y ambos con las figuras tenebrosas, como si todos los estamentos formaran parte de un mismo linaje. Esta es la herramienta, aquello que permite desde una dimensión instrumental captar el sentido de lo real.

El linaje nocturno dominado por la Hýbris también estará presente en los 'otros' humanos indeseables; habrá que ver cuáles son, pero se desprende claramente: los hombres que no trabajan, las mujeres por sus marcas de género, los reyes devoradores de dones y aquello que se corresponda con el viejo orden social. Además podemos pensar que el modelo del linaje, tanto diurno como nocturno, es el modelo o tipo social de lo Mismo y de lo Otro, en términos de Garreta; entonces, Nýx es análoga a la Mujer, al hombre que no trabaja, al injusto, a los reyes que imparten torcidos dictámenes. Lo que vemos en Hesíodo y sus construcciones discursivas es una primera distribución y asignación de roles y funciones, de valores, de espacios, que definen el campo de lo Mismo y de lo Otro. Ahora bien, estos linajes deben ser entendidos dentro de una lógica de la ambigüedad propia del discurso mítico que supone que las oposiciones no son excluyentes, no forman parte de una lógica de la no-contradicción que vendrá más tarde con la filosofía (Detienne, 1986:15-20). Los dioses son ambiguos en su naturaleza, y esto quiere decir que siempre tienen alguna relación estructural con otra divinidad opuesta; como dice Marquardt, "Darkness and light, although incompatible, are inseparable (e.g. Theog. 748-54), and Hesiod's depiction of 'golden' Aphrodite is incomplete without the sobering counter part of 'dark' Night" (1982:284).

Si Homero y Hesíodo trabajan indistintamente con una materia prima que es la espesura mítica, creemos ver en el último un tratamiento particular del material, una organización de otro orden, que responde a un universo que se está secularizando de cara al nacimiento de la pólis y que ubica al poeta en una región compleja, de límites poco claros entre filosofía y poesía (Detienne, 1986:97-108). El linaje como un operador discursivo y de sentido permite la ordenación del campo de lo Mismo y de lo Otro, resultando esta distinción un pilar en la obra hesiódica ya que, a partir de la arquitectura discursiva con la que nos enfrentamos, encontramos una línea de continuidad en ambos poemas.

Pensar a Hesíodo como novedad nos conduce a sostener la lógica del linaje presente en sus poemas como un núcleo que cohesiona la totalidad de la obra. El linaje a modo de operador discursivo hilvana esa totalidad que avanza, tanto en Teogonía como en Trabajos y Días hacia formas más justas y ordenadas ya sea en el plano cósmico-divino como en el plano social. Forma más justa y ordenada en la medida en que el linaje positivo triunfa estructuralmente sobre el negativo, ubicando a Zeus como el verdadero garante de la justicia (Gigon:1985), como rector del proceso de consolidación del orden y del poder.

A modo de conclusión parcial, podemos decir que quedan delineados en los dos poemas dos territorios conceptuales, definidos en términos de linaje, uno diurno y otro nocturno, uno positivo y otro negativo, uno de matriz luminosa, otro de cuño tenebroso, que permiten clasificar esa totalidad que incorpora tanto al mundo natural como al humano en un sistema compacto de significación. Esto no implica que no aparezcan ambigüedades y mezclas, bifurcaciones y atajos en el diagrama de fuerzas de esos dos linajes, el cual constituye la llave que posibilita las ambiciones de Hesíodo, de las que Rodríguez Adrados afirma: 
[...] ambiciones por así decirlo unitarias: esas grandes y complexivas descripciones que, además, al menos en el caso de los dos primeros poemas, representan una visión idealizada: el progreso del mundo consiste en la implantación del orden de Zeus, que garantiza la justicia (Rodríguez Adrados, 2001:199).

La progresiva organicidad de los tres sistemas, el cósmico, el divino y el humano, supone un diagrama de tensiones sobre las que se asienta dicha organización. Lo diurno y lo nocturno, lo positivo y lo negativo, lo aceptable y lo rechazable, lo legal y lo ilegal, lo justo y lo injusto reproducen, en última instancia, la tensión de opuestos que da cuenta de la naturaleza misma de lo real en su conjunto.

Potencias y divinidades se inscriben así en uno u otro linaje; reyes, hombres, mujeres, instituciones, comportamientos, estilos de vida, ciudades, se pueden leer desde una perspectiva u otra, al tiempo que edifican la arquitectura explicativa de la complejidad de lo real. Esta complejidad se define en el terreno agonístico de los contrarios en oposición, representando un claro antecedente de las formulaciones posteriores que hacen del pólemos el hilo que borda la constitución del universo como un todo ordenado.

\section{Las Moûsai y los reyes. Una duplicidad estructural}

A partir de aquí proponemos relevar la función de soberanía y el perfil del rey justo, inscrito en el linaje positivo a partir de una doble relación: su maridaje con las Moûsai y con la Justicia como modo de ser y obrar. Desde este doble andarivel, creemos ver en su figura la imagen del varón justo que puede con su obrar producir un efecto político sobre lo real y conjurar el efecto nocivo que representan los doróphagoi en el contexto de la aldea hesiódica. La acción política queda así asociada a los valores positivos y luminosos que el rey representa, al tiempo que se inscribe en una metáfora médica tendiente a sanar las nefastas consecuencias del obrar de los reyes devoradores de dones, causantes del daño de la ciudad.

Comencemos entonces por una relación emblemática en la línea del linaje diurno, esto es, el vínculo entre las Moûsai y el rey, en el marco de una asociación que se da en una misma inscripción de valencia positiva. Hesíodo se refiere a la acción de las Moûsai sobre los hombres en estos términos:

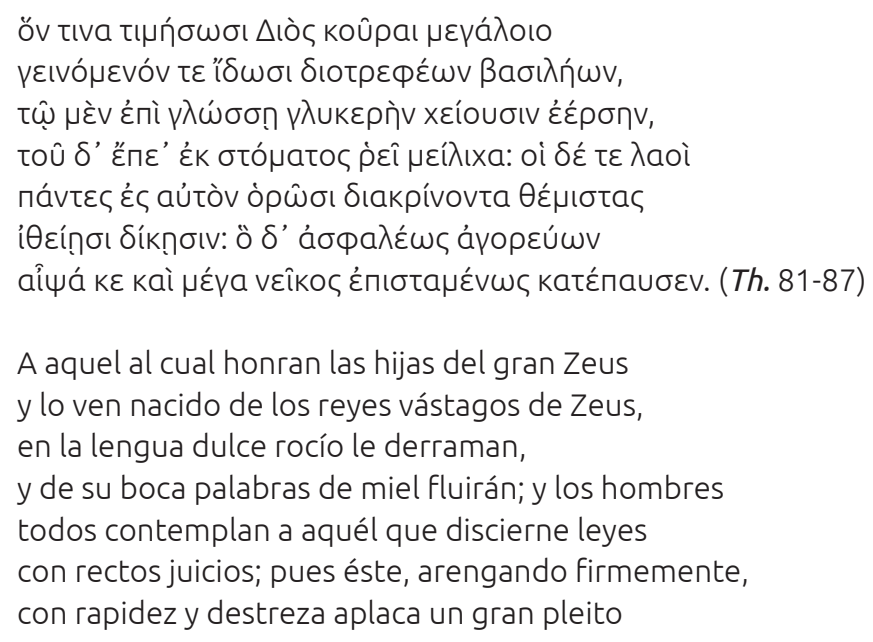


Los reyes reciben, pues, una doble filiación luminosa; son vástagos de Zeus, padre de todos los hombres y de todos los dioses, y son elegidos por las Moûsai que los miran al nacer, marcando con esa juvenil mirada un registro de poder que se inscribe en la función de soberanía. Para que las Moûsai cumplan su acción, 'realicen', siguiendo el campo lexical del verbo kraîno, 'realizar acabadamente', 'cumplir por completo', es necesario que el privilegio se materialice en don (Detienne, 1986:59-86); por eso derramaron sobre su lengua una gota de dulce miel para que de su boca fluyan melifluas palabras (" $\mu \varepsilon i ́ \lambda \iota \chi \alpha$ ", v. 84). En realidad las Moûsai otorgan a los reyes elementos que son propios de su naturaleza diáfana. Así como de ellas fluye el dulce canto que las convierte en las Bienhabladas hijas de Zeus, del mismo modo, de los reyes fluyen dulces palabras.

Pensemos en la voz, en las dulces palabras. La voz es un tópico dominante en el relato teogónico. Constituye el don privilegiado de las Moûsai, lo que posibilita el relato sobre los orígenes y permite al poeta-vidente narrar una teogonía y una cosmogonía como modo de celebrar a los Inmortales. La voz dulce y melodiosa de las bienhabladas hijas de Zeus se contrapone a otras de sesgo nocturno y tenebroso como la horrorosa voz que brota de la boca oscura de Tifón, criatura monstruosa que pariera Gea:

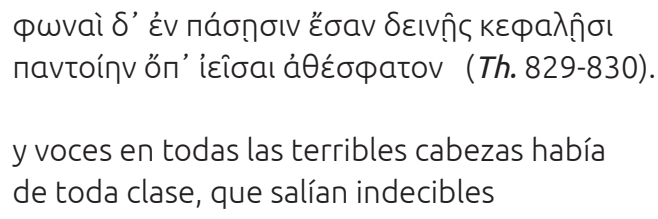

Otros tonos, otra dimensión de la voz, otros matices sonoros se despliegan en un tópos luminoso de carácter contrario a ese escenario de tenebrosidad dominante que el monstruo impone desde su extrañeza ontológica, brotando

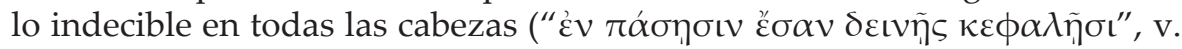
829), marca de su alteridad radical.

Ahora bien, no alcanza con rastrear la línea de la dulzura para comprender el maridaje entre ambos. Debemos considerar la capacidad interpretativa de los reyes para entender, a su vez, la ecuación saber-poder que legitima su liderazgo. Sabemos que toda estructura de saber implica una relación de poder y viceversa. ${ }^{1} \mathrm{El}$ rey interpreta las sentencias que son rectas y sin falla por venir de Zeus, abriendo así una línea de continuidad directa entre el Padre de todos los hombres y todos los dioses y él mismo como su vástago. Sobre los reyes recae de este modo una doble convergencia de la claridad divina, la de las Moûsai y la de Zeus, potencias emblemáticas de valencia positiva.

Este legado que se traduce en una particular capacidad es lo que le permite

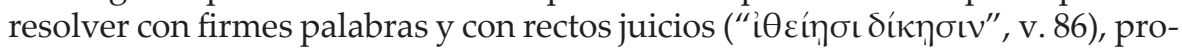

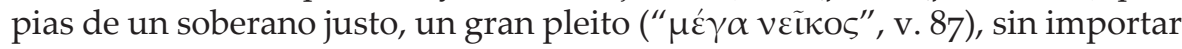
su envergadura. Es fundamental a la hora de mantener el orden en el espacio social, alejando los efectos de la éris gustosa del mal. Se trata del sostén de un estado de armonía que, de quebrarse, retrotraería el kósmos social a un estado previo de indefinición, asociado al kháos, aquel primerísimo elemento que el

1 Seguimos en este intento de lectura las indicaciones de Michel Foucault (1979) sobre el maridaje entre saber y poder como modo de trabar la relación que guardan las palabras y las cosas en un determinado momento histórico. El saber no es sino una estructura de poder que legitima la puesta en funcionamiento de ese saber producido históricamente. 
poeta narrara en su cosmogonía, especie de abismo, de vacío primordial que aún no posee las marcas de la definición cósmica.

Son las rectas sentencias las que se oponen a los torcidos dictámenes de los dorophágoi, diagramando así los tópoi a los que aludimos al comienzo y que el mito delinea en su dimensión significantel. Lo Mismo y lo Otro quedan configurados a partir de este doble ejercicio del poder, de esta dualidad radical en la gestión de las cosas justas, al tiempo que se instituye la dimensión de una soberanía de valencia positiva emparentada con Díke.

Son las rectas sentencias las que curan a la aldea de la enfermedad que los torcidos dictámenes acarrean, definiendo una función socio-terapéutica que

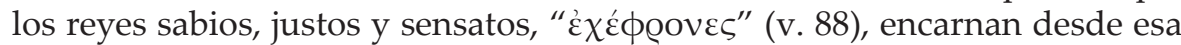
soberanía política. El rey es el hombre de la palabra justa, sabia y bondadosa; aquel que persuade con tiernas palabras, " $\mu \alpha \lambda \alpha \kappa o \tilde{l} \sigma \mathrm{\iota} . . . \dot{\varepsilon} \pi \varepsilon \dot{\varepsilon} \varepsilon \sigma \sigma \mathrm{v}$ " (v. 90), como herramientas de poder y autoridad.

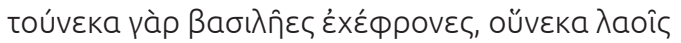

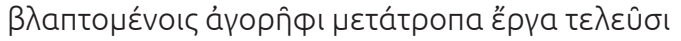

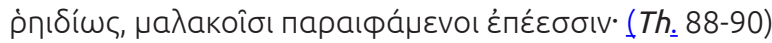

pues por ello los reyes son sensatos, dado que para los hombres dañados, en el ágora cumplirán acciones compensatorias fácilmente, apaciguándolos con tiernas palabras.

Es por este don de poder contemplar la justicia y reparar toda forma de agravio que el rey es merecedor del mayor de los respetos. Se trata de una figura como la de Nereo, el anciano del mar, el presbýtatos por excelencia porque jamás olvida la equidad y no posee más que buenos y justos pensamientos (Colombani, 2005). Si antes nos referíamos al orden de la aldea, ahora lo haremos al orden anímico de aquellos que se sienten agraviados. Siempre se trata de una misma función de protección y cuidado, semejante a la del padre de familia que Detienne relaciona precisamente con la imagen del rey bueno, conductor de rebaños (1986:39-58).

Hay otro rasgo que marca la dimensión política del rey: la persuasión. Se trata sin duda de una potencia de signo positivo, que se vincula directamente con las características que el poeta viene exponiendo. Las palabras complacientes

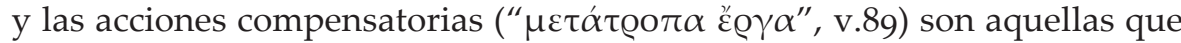
mejor persuaden a un auditorio que legitima el poder de quien las pronuncia.

Estamos entonces frente a la doble articulación de la palabra y la eficacia, y de la palabra y la persuasión, como notas constitutivas del ser mismo de la palabra, de su dimensión ontológica. En torno a la primera, coincidimos con Detienne cuando sostiene,

De hecho, en el sistema de pensamiento religioso donde triunfa la palabra eficaz, no hay ninguna distancia entre la "verdad" y la justicia: este tipo de palabra está siempre conforme con el orden cósmico, pues crea el orden cósmico, constituye el instrumento necesario para ello (1986:68).

Alétheia y Díke resultan complementarias en el marco de un sistema de relaciones que reconoce un telón de fondo mágico-religioso que legitima su funcionamiento y convierte a ambas potencias en las dos caras de una misma moneda. El segundo aspecto anuda las nociones de Pístis y Peithô, ya que Pístis revela 
una nueva dimensión: las relaciones de este tipo de palabra con los demás, dimensión que definirá igualmente el valor complementario Peithô. La Pístis es tradicionalmente "la confianza entre el hombre y el dios o la palabra de un dios" (Detienne, 1986:68). Podemos incluso extender las consideraciones y pensar en la confianza entre el hombre mortal y la palabra del rey por pronunciar las rectas sentencias que, al venir de Zeus, son las mejores. Esta confianza que convoca a la persuasión como par complementario legitima la autoridad del rey, en desmedro del poder que pretenden detentar los dorophágoi, torciendo las sentencias divinas. Estas marcas reactualizan la inscripción del rey en un linaje positivo y diurno, por lo cual lo veneran como a un dios (" $\theta \varepsilon \dot{v} v \omega \varsigma^{\prime}$ ", v.91). Quizás por eso,

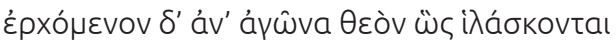

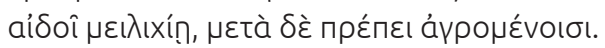

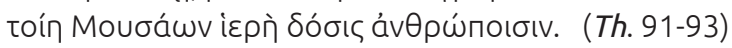

Al que llega a la asamblea, como a un dios propician con dulce respeto, y entonces sobresale entre los reunidos; tal es, de la Musas, el sagrado don para los hombres

Lo respetan como a un rey por su estrecha familiaridad con el Padre, familiaridad que se inscribe en una proximidad estructural. Zeus es el dios de la justicia y de las leyes divinas que impone su autoridad a través de la Díke. La justicia, en tanto Díke de Zeus, repara y endereza lo torcido "con rectas sentencias" (Teogonía, 86).

Este acto de enderezar y reparar es la función propia de Díke. Entre Thémis y Díke se encuentra una clara diferencia: mientras la primera se refiere a los mandatos o leyes divinas (de hecho, thémis era el asiento que ocupaban los reyes en la Asamblea para administrar justicia), la segunda tiene que ver con su recta aplicación, con el nivel de gestión o administración. Por eso Hesíodo insiste tanto en las torcidas interpretaciones de los reyes y, por el contrario, la recta interpretación y aplicación constituye el pasaporte al reconocimiento y el elogio, como condiciones de su soberanía política; es por ello que sobresale

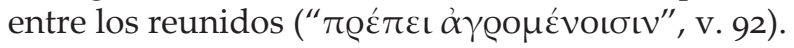

\section{Conclusiones}

El presente trabajo se ha propuesto pensar el ejercicio de la soberanía de los reyes vástagos de Zeus en el marco de un esquema más amplio que engloba la administración de la Justicia desde una dimensión positiva, en contraposición a una gestión de valencia negativa, representada por los dorophágoi. Desde este marco, vimos cómo los reyes toman las marcas identitarias de las Moûsai, lo cual los territorializa en un linaje positivo, de matriz luminosa, asociada al Día. Su acción se encuadra en el mismo registro benéfico que el de las hijas del Padre. Por eso de su boca brotan melifluas palabras, ya que ellas mismas han depositado una gota de dulce miel como legado-don de una condición excepcional. La continuidad está asegurada y la figura del rey de justicia coincide con la imagen del rey bueno.

El rey es intérprete de los dioses y con ello permeabiliza los planos que requieren de un sujeto excepcional para ponerse en contacto. Este punto emparienta al rey con el poeta, con el adivino, con el purificador, todos maestros de alétheia. 
En este sentido, conviene recordar aquí la cartografía de lo real que sostiene Gernet (1981) cuando habla de dos razas o dos mundos impermeables: el plano divino y el plano de los mortales. Un maestro de verdad como el rey puede, a partir de su excepcionalidad ontológica, permeabilizar esos tópoi y con ello achicar la distancia que separa un plano de otro. Su poder está también dado por el reconocimiento de todos aquellos que en él fijan su mirada, haciéndolo brillar en medio del vulgo, a partir de su capacidad y persuasión. En efecto, todos los hombres contemplan a aquél que discierne leyes con rectos juicios:

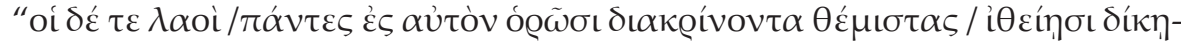
$\sigma \iota v "$ " (vv. 84-86). Es este brillo lo que confirma la metáfora lumínica propia del linaje diurno. El rey brilla y su brillo ilumina la acción política, que a su vez se ve beneficiada con sus sentencias rectas, opuestas a las sentencias torcidas, propias de los dorophágoi.

El rey aparece como aquel que ostenta el saber y el poder de interpretar la voluntad divina. La función de los reyes es la pieza clave para la conservación del orden, restaurándolo con su palabra cada vez que es dañado o reparándolo con su lógos firme y recto luego de haber sido mancillado por las ofensas. Interpretar y resolver sabiamente son los pilares sobre los que se asienta una acción de sesgo político, que mantiene la pístis sobre su figura y legitima su poder.

El rey constituye de este modo un operador de un tipo de Justicia divina que no conoce aún las pautas del derecho. En el marco del pre-derecho, propio de este esquema mental, interpretar las thémistes es su función y, al hacerlo, su autoridad debe restablecer, a través de las díkai, las decisiones divinas que han sido alteradas, al tiempo que refuerza su soberanía política en un sistema de creencias que hace del rey un ser excepcional, con un parecido muy fuerte a un dios. Las díkai resultan entonces los veredictos que pueden ajustarse o no a las thémistes, zanjando las diferencias entre los veredictos torcidos y los rectos y articulando la distancia entre los reyes buenos y sabios y los devoradores de dones.

Este trabajo nos ha acercado a poder establecer las complejas relaciones entre mito y lógos o mito y filosofía. Al ubicar a Hesíodo en el marco de un primer balbuceo filosófico, hemos tratado de suavizar las fronteras tajantes y férreas que históricamente han territorializado al mito y a la filosofía en espacios y estatutos diferenciados. Trabajar en el corrimiento de esas fronteras, es asumir el desafío de la desconstrucción.

Nos interesan los orígenes, los linajes y nos apasiona revolver los bajos fondos para descubrir en esos pantanos magmáticos los gérmenes, las procedencias, las contaminaciones, los azares, los desvíos que hicieron posible los objetos de pensamiento y discurso. Hesíodo piensa temas filosóficos con las reglas específicas de la formación discursiva que el mito impone como lógos sacralizado, y que, como corresponde al dispositivo, se imponen y "hablan" desde su ficción de época. El mito tiene la potencia reveladora de un tema de alto impacto filosófico. En ese sentido es un operador de sentido, un vehiculizador de pro-blemata, de obstáculos, de promontorios a sortear por estar íntimamente inscritos en nuestra condición de existentes, en estos seres capaces de asombrarnos y maravillarnos que somos. 


\section{Q Bibliografía}

"Colombani, M.C. (2016).Hesíodo. Discurso y Linaje. Una aproximación arqueológica. Mar del Plata: Editorial de la Universidad de Mar del Plata.

» Colombani, M.C. (2005).Hesíodo. Teogonía: una introducción crítica. Buenos Aires: Santiago Arcos editor.

»Detienne, M. (1986).Los maestros de verdad en la Grecia Arcaica. Madrid: Taurus editores.

"Foucault, M. (1983).El orden del discurso. Barcelona: Tusquets.

» Foucault, M. (1964). Las palabras y las cosas. México: Siglo XXI.

" Garreta, M, y Belleli, C. (1999). La trama cultural. Textos de Antropología. Buenos Aires: Caligraf.

» Gernet, L. (1981).Antropología de la Grecia Antigua. Madrid: Taurus.

» Gigon, O. (1985).Los orígenes de la filosofía griega. Buenos Aires: Gredos.

"Rodríguez Adrados, F. (2001). "La composición de los poemas hesiódicos", Emerita $69.2,197-223$. 
